\title{
الإسلام والثقافة العربية في عالمنا الجديد
}

\section{الشيخ محمد الغزالي}

لعل الفتوح الإسلامية كانت أسرع الفتوح في تاريخ العالم وأبعدها أثراً؛ ففي خلال عشرين سنة بعد وفاة صاحب الرسالة الخاتمة كانت أركان الدول الكبرى تنهار، وكان الاستعمار العالمي يتقلص كما تتقلص الظلمات أمام مطالع النهار... فقد للرومان أملاكهم في إفريقية وآسيا، وتحررت شعوب احتبست قروناً داخل مصيدة محكمة من البطش.

نعم تحرر في الشمال الإفريقي ما يسمى الآن مصر وليبيا وتونس والجزائر والمغرب، وتحرر من آسيا فلسطين وسوريا والأناضول، وحاول الفاتحون تحرير القسطنطينية فعجزوا، ولكنهم حرروا جزر البحر المتوسط تقريباً. وكان جناحهم الشرقي في آسيا قد محا دولة الأكاسرة ووصل شمالاً إلى جنوب روسيا وأوغل في الشرق حتى أخذ أقطاراً من الهند والصين.

إن الدولة الإسلامية الأولى تكونت في زمن خارق للعادات في قصره، وأقامت حضارة لا تزيدها الأيام إلا قدرة على البقاء ومقاومة الأحداث.

$$
\text { ويرجع ذلك فيما أرى إلى أمرين: - م }
$$

الأول: حاجة العالم إلى تعاليم الإسلام، واقتناعه بها ورضاه عنها عندما بلغته، حتى أن أبناء البلاد المفتوحة سابقوا العرب إلى فقه الإسلام ونشره، وصاروا أئمة للأمصار الكبرى تثق الجماهير بكم وتصدر عنهم. الثاني: أن أصحاب محمد صلى الله عليه وسلم قدموا الرسالة للناس علماً ذكياً وثقافة أصلية.

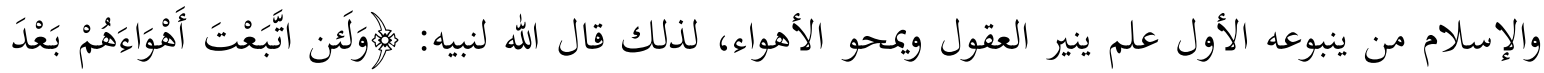

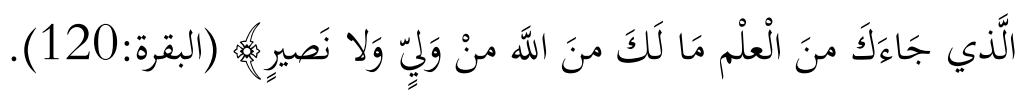




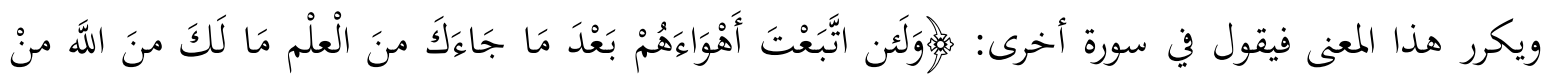

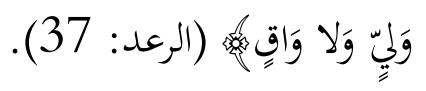

إن الإسلام علم واسع الدوائر، وقرآنه الكريم كون مسطور يضارع الكون المنظور في تفتيق العقول وبتحلية الفطرة.

ولولا ما في آيات القرآن من هدى ونور ما قامت أزهى حضارة في التاريخ! إنني رمق الأوج الذي ينقل القرآنُ

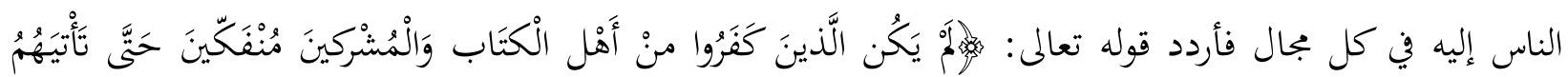

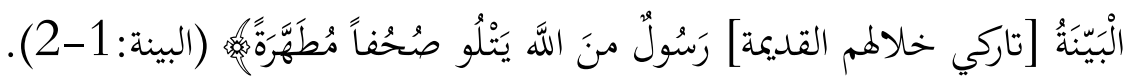

ثم أشعر بالأسى للأمية الثقافية التي لفت جماهيرنا في أكفاها وجعلتهم في هذا العصر آخر الأمم وأنزها رتبة. نعم، هناك أشرطة حية تحفظ القرآن حرفاً حرفاً ولا تعي منه ما يرفع رأساً. وهناك عشرات الدول تنتمي إلى الإسلام تذكرنا بتغلب وحمْير وطسْم وجديس. ماذا حدث؟ إن الإسلام الذي سمّيّ في وحي الله علماً أمسى أهله أسوأ الأميين في العالم...!! تذكرت الأيام الأولى من عمري عندما كنت أحفظ القرآن الكريم -من سبعين سنة مضت. كنا نتعلم الحساب في كتاب تضمن القواعد الأربع مترجم عن الإنجليزية ألفه مستر "تويدي"! قواعد الجمع والطرح والضرب والقسمة نأخذها عن خواجة؟! إن آباءنا وضعوا طائفة من النظريات الهندسية، وبرعوا في حساب المثلثات والمربعات فما الذي عرانا؟

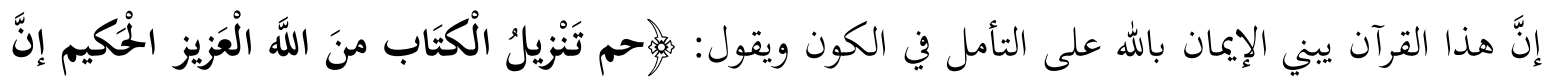

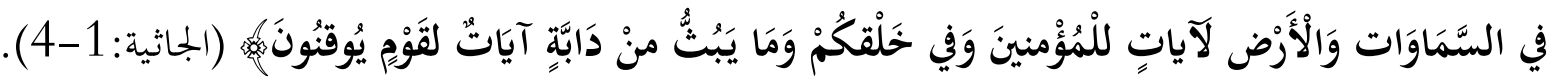
عناصر الكون ومظاهره هي مصادر الإيمان واليقين، فما يصنع مكفوف لا يرى آية؟ وما تكون معرفته لله؟ وهل المعرفة المزعزعة تضبط شهوة أو تحكم سلوكاً؟ أو تقتحم عقبة؟ أو تدفع إلى مكرمة؟ 
لقد بدأت بذكر المعرفة الكونية لأغا من شؤون الدنيا التي نستوي فيها مع غيرنا، والتي قيل لنا فيها أنتم أعلم بشؤون دنياكم!

$$
\text { ابتدع ما شئت! واكتشف ما استطعت! لا قيد ولا حظر. }
$$

إن غيرنا سبق سبقاً بعيداً وبرز في كل ميدان، وساند عقائده بما استطاع، فانطلق الباطل في ساحات الحياة مدرعاً بالحديد.

والتقينا به ونحن نحمل مواريث الوحي وأيدينا عزلاء وأجسادنا عارية، فلما عدنا كانت هزائمنا مضاعفة لفراغ اليد والعقل والفؤاد!

والألوف المؤلفة من مسلمي العالم يعيشون أتباعاً مغموصين لأهم يشترون أجهزةم المدنية والعسكرية من خصوم العقيدة وكارهي الوحي!! وينتظرون من الباعة أن يعلموهم ماذا يصنعون بهذه الأجهزة وكيف يستخدموها؟ أما ثقافتنا الإسلامية التي استبحرت في القرون الأولى فقد رأيت تأليف كتاب فيها سميته تراثنا الفكري في ميزان الشرع والعقل؛ والكتاب على وجازته يلقي ضوءاً على موضوعه وقد يحتاج إلى زيادة! إن عندنا مدرسة الفقه والتشريع ومدرسة التربية والأخلاق ومدرسة العقائد والمتكلمين ومدرسة التفسير والحمديث، وفنون الآداب من شعر ونثر. وقد تعرضت هذه المدارس للمد والجزر، والغزارة والضحالة، ووضعها الآن يثير الدهشة. فالأدب مثلاً كان في الجاهلية والإسلام شيئاً له وزن وقيمة. وقد ظل ينحدر حتى فقد وزنه، ثم فقد قيمته، ونحن الآن نقرأ شيئاً اسمه الشعر المثنور

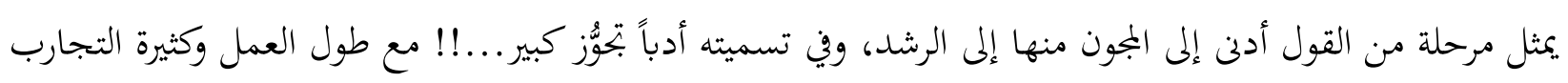
يتحكم العقل وهتدي إلى الصواب؛ وإذا كان ذلك مأنوساً في الأفراد فيجب أن يكون مألوفاً بين الجماعات والأمم. ونحن المسلمين نحمل رسالتنا من زمن طويل، إننا الآن في القرن الخامس عشر من تاريخ الإسلام، ذقنا مع دينا

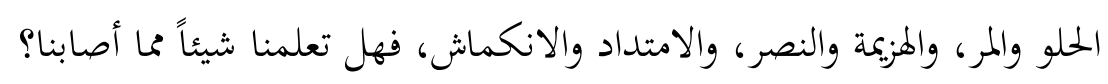

وهل استفدنا من التجارب حكمة تصقل أحكامنا وتضبط خطانا؟ المؤمن لا يلدغ من جحر مرتين، وربما قلت

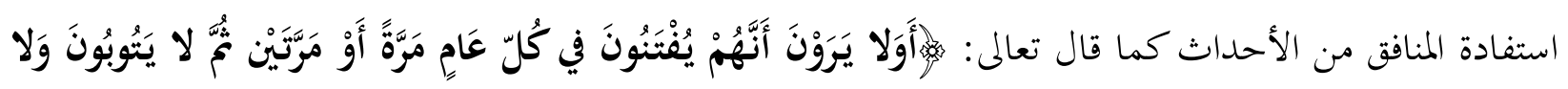

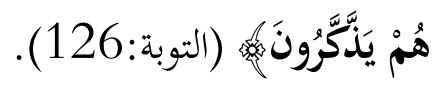


ولست أتساءل الآن عن مدى اعتبارنا من سقوط الخلافة العباسية في بغداد، أو سقوط الخلافة العثمانية في الآستانة، أو ضياع الإسلام كله في الأندلس، ثم بدء الانسحاب من الأقطار أوربة الأخرى!!، مع أن هذا التساؤل مطلوب وتحاهله جريمة.

إنما أتساءل عن المدارس العلمية المختلفة في الفكر الإسلامي، ماذا حدث لما؟ وأين حطت عصا الترحال؟ ولأبدأ بمدرسة التربية والأخلاق التي اشتبكت في تاريخنا العلمي بنزعة التصوف وفلسفته.

يجب فض الاشتباك السيّئ في هذا المجال وتنشئة أجيال أزكى نفوساً من المسلمين المعاصرين لا تفصل بين الإيمان والخلُق، ولا بين العبادة والخُقُ. إن الذي شان الخوارج قديماً وحديثاً ضعف أخلاقهم وهم يعاملون الناس، واستباحتهم المجنونة للدماء والأموال من أجل فكرة غلبت عليهم أو وجهة ساروا إليها. إفم لا يتواضعون لله ولا يهضمون أنفسهم لأمر ذي بال! أعجبني ابن القيم كبير الصوفية في عصره فيقول متواضعاً: إذا كنت قد عرفت شيئاً لم يعرفه الشيخ الكبير فأنا

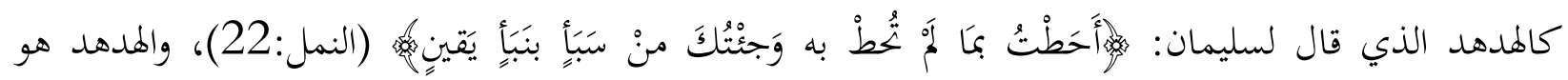
الهدهد، وسليمان هو سليمان!

ومضى الرجل في كتابه يعارض حيناً ويؤيد حيناً، وكأنه الشافعي الذي قال: ما جادلت أحداً إلا تمنيت أن يكون الحق إلى جانب!!

أين هذا الخلق من أشخاص مسعورين، همم الأول تحقير الخصوم والنيل منهم؟ فإذا جادلوا عن رأي لهم تقمصهم حب الانتصار وإثبات الشخصية والزهو بين الناس!. إن محنة التربية هائلة في العالم الإسلامي سواء في الأخلاق الربانية أو الأخلاق الإنسانية. الإخلاص لله قليل، والصدق مع الناس قليل، والمفروض أن نكون وراء نبينا نتمم مكارم الأخلاق. لا قيمة لأشكال العبادات إذا لم يكن وراءها مهاد من تقوى القلوب. والدين قبل كل شيء زكاة في النفس، وصفاء في الروح، وميل إلى العطاء لا الأخذ، وإلى السلام لا الخصام. 
ولأمر ما علّمنا نبيُنا أن أول ثلاثة تسعر بكم النار هم المرابون بالعلم والجهاد والصدقة.

إن المرائي يرى نفسه ولا يرى ربه، إنه مشغول بجاهه ومكانته قبل كل شيء!

وإذا عجز الدين عن كبت الغرائز السوء ومحوها، فإن تطبيقه في الحياة لن يكون إلا تنفيساً عن هذه الغرائز ولو

أخذ صورة العبادة!

وقد راقبت حركة إسلامية فشلت في بلوغ غاياتا، كانت تضم صالحين كثيرين ولكن بينهم عصابة ترى أن تحكم هي بما أنزل الله، وترفض أن يحكم غيرها!! إن حب الرياسة خالطها وهيمن على خططها وبواعثها فنشأت عن ذلك فتن هائلة...

ولله وعد بالتمكين مَنْ هدفهم إقامة الصلاة، وإيتاءُ الزكاة، والأمرُ بالمعروف والنهي عن المنكر، قبل أن يكون هدفهم تولي منصب ما... إن الأخلاق بقسميها الرباني والإنساني هي الإسلام الحق. يقول علي بن أبي طالب: "أيها الناس إني سمعت رسول الله صلى الله عليه وسلم يقول: يخرج قوم من أمتي يقرؤون القرآن، ليست قراءتكم إلى قراءقم بشيء، ولا صلاتكم إلى صلاتم بشيء، ولا صيامكم إلى صيامهم بشيء، يقرؤون القرآن يحسبون أنه لهم وهو عليهم، لا بتحاوز صلاقم تراقيهم، يمرقون من الدين كما يمرق السهم من الرمية"! والأجهزة الإدارية في العالم الإسلامي مصابة بمن يعبدون مناصبهم ويستغلوفا لمصالحهم ولا يعرفون أغها أمانات يُسألون عنها يوم الحساب.

وعلم القلوب الذي يسمى الآن علم التصوف لا يدري شيئً عن علل الأمة، بل هو تائه وسط أفكار وفلسفات سقيمة، ثم هو بين العوام رقص هتنز به الأبدان وتموت فيه العقول والأفئدة.

وأذكر أني في صباي قرأت كتاباً يتتبع الأمانة في مسالك الناس -وأظن المؤلف أمريكياً- فاستغربت أنه قرّب الفضيلة من الأذهان وكان عملياً واضحاً في إثبات السلوك الشريف ومحو السلوك الخائن. قلت ما أحوجنا إلى مثل هذا التأليف في ميدان التربية، حتى يكثر الأمناء بيننا! إن نبينا عليه الصلاة والسلام خلّف لنا ميراثاً ضخماً يدفع الناس دفعاً في طريق الكمال، ويصحبهم في مراحل الطريق بالتوعية والتذكير حتى لا تزل قدم أو تعرض ريبة. 
ما أحوجنا إلى هذا الميراث ونخن نواجه حضارة ذكية شريرة مغرورة.

أظن كتب الفقه الإسلام تبلغ نصف المكتبة الإسلامية، فإن اشتغال المسلمين بالفقه غلب على ثقافتهم وتغلغل بين عامتهم وخاصتهم، وإن لاحظنا بجزن أن الاهتمام بالفروع الصغيرة غلب على العبادة والمعاملات.

أما الفقه الإداري والاقتصادي والسياسي فإن البحوث فيه قليلة، ولعل بعضها كان مقلقاً!!

وقد كتب تلميذا أبي حنيفة -أبو يوسف ومحمد بن الحسن- في هذه الثؤون. ألّف الأول في الخراج أو الضرائب، وألف الثاني في الشؤون الدولية.

والميدان فسيح ليقول الفقه الإسلامي كلمته في نظم الحكم وقضايا المال وأطوار أخرى جدت في أنواع المعاملات.

والطريقة التي درسنا بها الفقه في صبانا الباكر ونحن في المرحلة الابتدائية بالأزهر جديرة بالتنويه.

فقد كنت حنفي المذهب كما أراد أبي، وكان زملائي بين الشافعية ومالكية، أما الحنابلة فقليلون. وكنا نتبادل الخلاف الفقهي ونخن نتضاحك! يقول المالكي الشك ينقض الوضوء، وأقول لا ينقضه! أو يقول المفطر ناسيا يقضي يومه، وأقول لا يقضيه!

ويقول الشافعي لمس المرأة ينقض الوضوء، وأقول لا ينقضه! أو يقول ينبغي رفع اليدين قبل الركوع وبعده، وأقول لا يرفع إلا عند تكبيرة الإحرام! ومع هذا الاختلاف المتبادل كنا زملاء متحابين نؤلف المظاهرات ضد الاحتلال الإنجليزي ونتعاون في مصالح شتى.

وما فكرنا قط أن يكون هذا الاختلاف مثار خصام أو عدوان.

ويظهر أن بعض البيئات في العالم الإسلامي درست فقه الفروع على أسلوب آخر زَرَع الجفاء والفرقة بين المسلمين.

وأذكر أني مكثت في الجزائر بضع سنين أصلي وراء أئمتها وهم مالكية دون حرج وفي يوم ما جاءنا حنبلي زائراً وصلى معنا، وكان يجاورين في الصف، فرأيته مضطرباً غضبان يوشك أن يعيد صلاته، وأن يأمرنا بإعادة الصلاة!. 
قال أرأيت هذا الإمام يكبر ثم يقول مباشرة الحمد لله رب العالمين؟ قلت له: الإمام مالك لم يثبت عنده حديث الاستفتاح، ولم يثبت عنده أن يستغيذ المصلي... وليست البسملة جزءاً من الفاتحة، وله رأيه ولك مذهبك. ألم تقرأ كتاب ابن تيمية رفع الملام عن الأئمة الأعلام؟ هذا تنوعٌ وليس اختلاف تضادّ، والمرويات الواردة تنسب إلى الرسول عليه الصلاة والسلام هذا وذاك من الأقوال فاسكت ولا تحدث بين الناس فتنة! والواقع أني أكرهت الرجل على الصمت وأحسبه لمج يصل معنا بعد ذلك اليوم...

لقائل أن يقول: ما هؤلاء الأئمة الذين ذكرت أسماءهم وربطتنا بهم؟ إننا نمضي بعيداً عنهم وما نحب أن نعرج

وأجيب: لك ذلك إذا شئت، والمهم أن تكون ماهراً في القرآن، خبيراً بالسنن، ضليعاً في اللغة، ألمعياً في الذكاء،

$$
\text { مستغنياً عن تجارب الآخرين! }
$$

إن هؤلاء الأئمة سبقوا في دراسة الكتاب والسنة ولم يجيء أحد منهم بشيء من عند نفسه. وقد عُرفوا بالعلم والتقوى، وخدموا الإسلام جهدهم، ولم يجمعوا الناس حولمم بالعصي أو بالعطايا.

إذم مدارس مجتهدة، تخطئ وتصيب، وهم جميعاً مع مالك في قولته المشهورة: "كل امرئ يُؤخذ منه ويرد عليه إلا صاحب هذا المقام" [يعني رسول الله صلى الله عليه وسلم]، وأشهد أهم قمم شوامخ في فقه الإسلام وفي التجرّد لله وازدراء العاجلة.

وما رأيت أهل علم زهدوا في تراثهم، أو زُعم لأحدهم العصمة. وعل أي حال فقانون الاجتهاد أن من أصاب له أجران، ومن أخطأ فله أجر واحد. ورأيي أن باب الاجتهاد مفتوح، ولكن يستحيل أن نأذن لكل إنسان بولوجه.

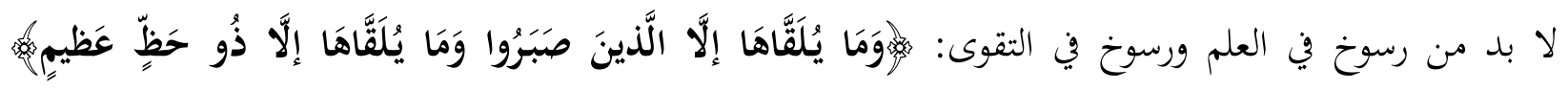
(فصلت:35). وميدان الفقه تعمل فيه شعبتان: أصحاب الرأي، وأصحاب الأثر. وليس معنى الرأي الهوى، وليس 
معنى أصحاب الأثر أن من المسلمين من يترك نصاً وارداً. وإن الطبائع العقلية للبشر مختلفة، فقد يفهم واحد من النص ما لا يفهمه غيره.

وتدبَّر حار الصحابة في تنفيذ قول الرسول "من كان يؤمن بالله واليوم الآخر فلا يصلين العصر إلا في بين

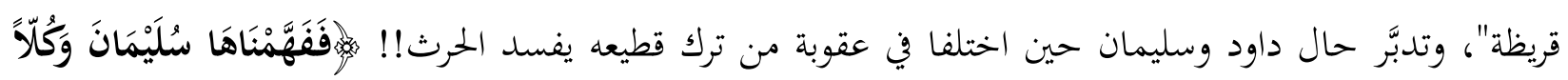

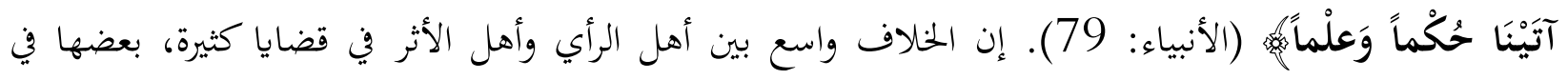
العبادات وبعضها في المعاملات، لكن ما قيمة هذا الخلاف؟

إنه في بعض الفروع والتفاصيل، وما يجوز أبداً أن يفسد وداً أو يوقع خصاماً! إن الأساس الذي نخرص عليه هو العقائد والأخلاق، إنني أميل إلى مدرسة الرأي مع احترمي لأمدد بن حنبل وتقديري لصلابته وتقواه... وأشعر أحياناً بأن الخلاف - في الفروع والتفاصيل- جزء من المجتمع الواحد، ففي الولايات المتحدة حزب للديمقراطيين وآخر للجمهوريين، إغما متفقان في الولاء لدولتهم والانتصار لها عالمياً، ومع ذلك فالجدال بينهما مستمر في شؤون شتى. فلماذا يتطير البعض من الخلاف الفقهي عندنا وينادي بالويل والثبور وعظائم الأمور؟

أفدت من بحارب كثيرة أن درساً في الطب أو الفلك أجدى على الإيمان من حوار فلسفي طويل. وذلك فج القرآن الكريم.

فإنه يكشف عن الحق برؤية آيات الله في الأنفس والآفاق.

خَرَ

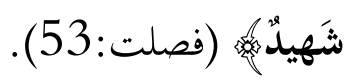

بعد ساعة من تناولي الطعام أقول لنفسي: بدأ العمل في إخراج الحي من الميت والميت من الحي.! كيف؟ إن الطعام -وكان مادة جامدة- أخذ يتحول داخل جسمي إلى دماء فيها الكرات البيضاء والحمراء، وإلى شعور وأظافر،

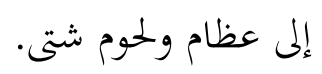

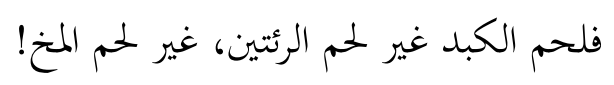


وللخلايا خصائص وراثية وطائة، وللغدد وظائف تقوم بها، ونخن لا ندري.

والروح الذي يتخلل هذه المادة ويجعلها خلقاً آخر، ينبعث من الحيّ القيوم. ليس لدي وحدي، بل في ألوف مؤلفة من الأحياء. ثم يطرد هذا البدن ما لا يستفيد منه ليتحول في بطن الأرض شيئاً آخر. قد يصير سنابل حافلة بالحبوب، أو نخيلاً مرصعة الصدر بالطلح النضيد، أو كروماً يتدلى منها العنب عناقيد كثريات الذهب!! أنباء أنا أو أنت وراء هذا التحول؟ أم رب الأرباب؟ لو كان لأوامر الله -وراء كل خلق- صوت يسمع، لصُمَّت الآذان من كثرة الأوامر بالإنشاء والتكوين.

$$
\text { ما ما أجمل الله، وأحلى صنعه! أحياناً أردد هذا الغناء: مائباً لا يغيب }
$$

إن الإسلام فطرة سليمة، وعقل سوي، وصراط مستقيم، وهو طبيعة العلاقة بين مادة الكون وبارئها الأعلى.

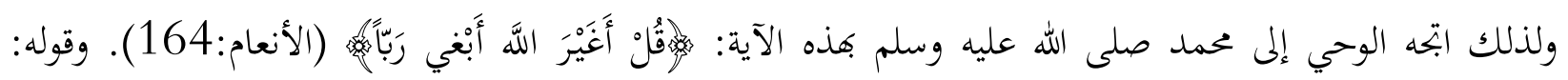

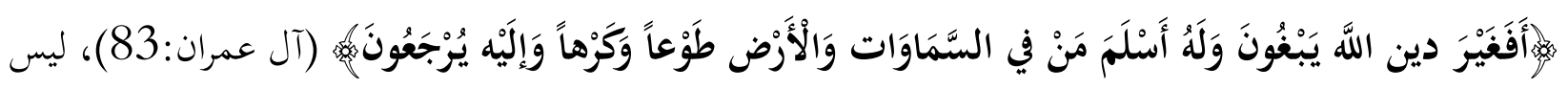

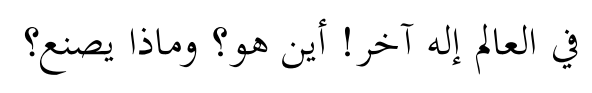

$$
\text { إن الشرك وهم مغفل كبير، أو حلم لنائم منفوخ البطن مُسهد المضجع! }
$$

ومع ذلك فالجاهلون بالله كثيرون، ويخيل إلى أن جريرقم، بقدر ما تعود إلى غبائهم، تعود إلى تفريط المسلمين في خدمة الحق وفتنة الناس عنه والعجز المستغرب عن اقتياد التائهين إليه... ليس بين المسلمين خلاف في العقائد،

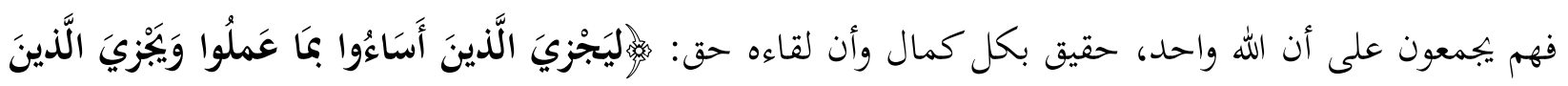

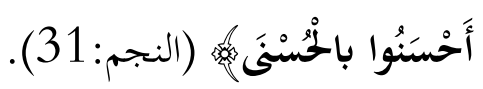

وقد تسللت إلى العقائد المقررة أفهام وأوهام من صنع الناس لا يعرفها القرآن الكريع ولا يقرها. وحسبنا كلام الله... وخذ مثلا: مبحث الصفات الإلهية: أهي عين الذات أم غير الذات أم لا عين ولا غير؟ وهذا تساؤل سمج 
يجب دفنه ومنع اللغط فيه، وخذ مثلاً: أعمال الناس أهي من خلقهم أم من كسبهم، وهل هم مخيرون أم مجبورون؟ وهذه أسئلة بالغة السخف، والمشتغلون بها هاربون من مستشفيات المجانين، ومن قال لا عقل لي ولا إرادة فعلاجه العصا! وفي مباحث العقائد: هل البعث للأجساد الأولى أم لأجساد مماثلة؟، وهذا كلام ولدته البطالة ولا قيمة له! لعل أفضل ما يغرس الإيمان الحق هو منهج القرآن نفسه، وقد قرأت في مؤلفات العصر الحاضر كتاب العلم يدعو إلى الإيمان وكتاب الله يتجلى في عصر العلم؛ ولو طُعّم هذان الكتابان ببعض الآيات القرآنية لكانا أفضل من كتب كثيرة

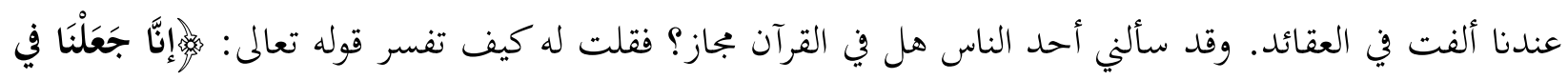

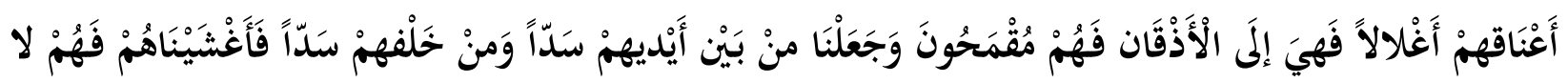
يُبْصرُونَهُهِ (يّس:8-9)، هل السدود هنا سد أسوان وسد الفرات؟ إن المجاز موجود في لغة العرب، وفي لغات الناس الأخرى، ومع ذلك فما دخل هذا في العقائد؟

قال: هناك من ينكر بعض آيات الصفات ويتكلف تأويلها، قلت: هناك مرويات تتصل بذات الله تعالى لا يليق بالعقل البشري أن يحاول معرفة كنهها، إن البحث وراء المادة ليس من وظيفة العقل البشري. وهناك مرويات يستحيل تركها على ظاهرها، ولا بد من تأويلها مثل: "مرضت فلم تعدني" و"... كنت سمعه الذي يسمع به، ورجله التي يمشي بها". ومع ذلك فما معنى اشتغال الدهاء بهذه المرويات وعكوفهم على ترديدها؟ هذه بطالة مقنعة وتسكعٌ في طريق الحياة لا مساغ له... إن سلفنا الأول كان سليم الفطرة، خالص النية، لزم الجد في الأمور، فحكم الدنيا بدينه، ولو اهتم بهوامش العقيدة التي افتريناها ما أحرز نصراً ولا فتح بلداً.

وعندما شرف الله العرب بحمل الرسالة الخاتمة، حذرهم الفرقة وأوصاهم بالجماعة، وقال لهم كما قال لمن قبلهم:

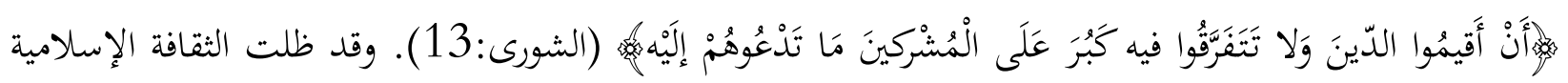
طوال ألف عام أو يزيد توفر للأمة عناصر الوحدة وبتعلها أمام عدوها جبهة واحدة.

لا الفقه المذهبي ولا هوامش العقيدة ولا الأخطاء السياسية الفاحشة أفلحت في تقطيع الأمة الإسلامية وتمين أعدائها منها، حتى ظهرت بدعة القوميات في العصور الحديثة، وانتقلت جرثومتها إلى أرضنا، فإذا هي بلاء يهدد الحاضر والمستقبل. وكان ظهور "القومية الطورانية" في تركية أول الغدر بأمتنا الكبيرة وأول زلزال يصدع بناء الخلافة 
واليهود نقلوا هذه الجرثومة إلى تركية انتقاماً من السلطان عبد الحميد الذي رفض باسم الإسلام أن يستوطنوا فلسطين. ومع أغم أغروه بالمال -وكان إليه محتاجاً- فقد أبى. ومع أن أوربة كانت تظاهرهم، فقد شعر الرجل المؤمن بأن تسلل اليهود إلى فلسطين تمهيد لضرب الإسلام نفسه في أوطانه كلها... فماذا يفعل اليهود؟ لجأوا إلى الغزو الثقافي، واستعانوا بقوى خفية وأخرى جلية على إنشاء "جمعية الاتحاد والترقي" ونشروا مبادئها القومية بين ضباط

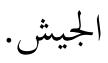

فقامت ثورة أودت بالخليفة، وكان رد الفعل نشوء القومية العربية التي ظاهرت الحلفاء في الحرب العالمية الأولى حتى انتصروا، وتمخضت هذه الفتن الهائلة عن سقوط الخلافة الإسلامية في العالم.

وتتابع الاهيار حتى قامت ثورات مشاهمة للثورة الكمالية استغنت بالقومية عن العقيدة وجعلت الإيمان -إلى حين- ضيفا ثقيلاً ينتظر منه الرحيل! إن جماهير المسلمين لا تتنازل عن دينها ولا تعدل بجامعته شيئاً، والذي حدث أن الاستعمار العالمي أول ما نزل بلادنا ألغى الشريعة واستبدل أحكامه الوضعية بأحكامها السماوية! ثم وضع خططاً بعيدة المدى للإجهاز على بقايا الإسلام من أخلاق وعبادات وتقاليد، واستعان على بلوغ أغراضه بنفر من الطامعين والمنحلّين -وهو يتربص بنا الدوائر وينتظر مع مرور الزمن أن يمحو الإسلام كله من على ظهر الأرض!

والحرب بينا وبينه سجال، وهي حرب رحبة الميادين، وأسلحتها لا حصر لها... لقد استطاع أبو بكر أن يهزم أعداء لله في أول قتال مع المرتدين. فهل يستطيع رجالات الإسلام في القرن الخامس عشر للهجرة أن يستعيدوا شرائع الإسلام التي عطلت، وأن يحموا العبادات المهددة بالزوال، وأن يستبقوا المعروف معروفاً والمنكر منكراً؟ إذا اهزمنا في هذه المعركة فلن يبقى على ظهر الأرض مؤمن... شبكات التنوير في تعاليم الإسلام ترسل أشعتها على جبهات

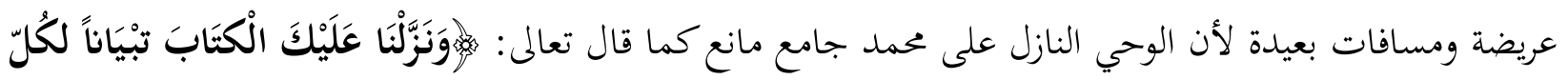
شَيْيَهِ. (النحل:89)، وعندما يكون الدواء مركباً من سبعين عنصراً، فإنه لا يحصل الشفاء الكامل إذا نقصت منه بضعة عناصر، بل قد يوصف الدواء -والحالة هذه- بأنه مغشوش؛ ولعل ذلك ما بيّنه الرسول الكريم في قوله: "الإيمان بضع ومبعون شعبة، أعلاها لا إله إلا الله، وأدناها إماطة الأذى عن الطريق، والحياء شعبة من الإيمان". فالإسلام ينظم شؤون البيت والشارع، والمدرسة والديوان، وعلاقات المرء مع نفسه والآخرين، وواجباته في الحرب والسلم، وضوابط المعاملات الاقتصادية الرحبة. 
وهو يعتبر الإنسانية رحمة عامة توصل بالتعارف والحُُقُ، كما توصل الرحم الخاصة بالتزاور والعطاء.

وين الكتاب المبين والسنن الشارحة ما يوضح جوهر هذه الرسالة العالمية الخاتمة، والمفروض أن يعرف المسلمون رسالتهم كما نزلت إليهم، وأن يبينوا للناس كافة، وأن يكونوا في حياتم الداخلية صورة حسنة لها. وإذا وقع قصور في الفهم أو تقصير في البلاغ فهم مسؤولون عن ذلك في الدنيا والآخرة. ولست هنا أسائل نفسي وقومي عما كان منا وما نزل بنا في هذه الأيام النحسات، فإن أيام المدّ ذهبت وأعقبها جزر مزعج، وعلى قدر الجبهة التي عمل الإسلام كان الغزو العلمي والمدني الذي تعرضنا له! كان اقتحامُ أخلاقنا يتم في وقت واحد مع اقتحام حدودنا. وإنني لأدرس المسرحيات التي تعرض من خلال وسائل الإعلام المختلفة، فأشعر أها تبدّل ثيابنا الداخلية والخارجية كما تبدل في الوقت نفسه أحكامنا على الأمور وتصورنا للحاضر والمستقبل!

إن سقوط بغداد وقرطبة أقل في نظري من سقوط أحكام العبادات والمعاملات! ورضا العامة والخاصة بتعطيل النصوص، وتحقير المثل الإسلامية، أبشع في نظري من هب خيراتنا وتحقير أوضاعنا... ومن هنا فإن إحياء الثقافة الإسلامية الصحيحة، وتكوين جيش شجاع للمحافظة عليها في الداخل والحديث عنها في الخارج أهم ألف مرة من تحقيق الاستقلال السياسي لبلد ما في إحدى القارات... - م ما قيمة هذا الاستقلال إذا فقدنا فيه علاقتنا بكتاب ربنا وسنة نبينا؟ مسالك أهل الكتاب من قبلنا كانت السبب الأول في المعركة بين العلم والدين، وقيام عصر الإحياء في أوربة بعيداً عن الوحي كله!! ويبدو أن القوم لم يتغيروا، فقد وقعت أخيراً معركة في الكنيسة الإسرائيلي بين وزير الخارجية وبعض الحاخامات سببها أن الوزير قال: "ليس كل ما فعله الملك داود جديراً بالإعجاب!"، مشيراً إلى ما نُسب إلى داود في العهد القديم من اقتراف جريمتي الزنا والقتل. قالوا زنى بزوجة "أوربا" الحنَّى ثم أوصى بقتله في الميدان حتى لا يعود، ويسترد المرأة من عشيقها الملك!! لقد غضب الحاخامات من هذا التعريض. وقالت إذاعة لندن إظم سيحرجون الحكومة كلها في أول اجتماع... ونترك بني إسرائيل لنرمق تاريخ الكنيسة القريب والمعاصر. لقد جاءت من أوربة إلى إفريقيا لتبشر بالمسيح حامل الآلام عن هذا الورى -كما يقول شوقي- فماذا فعلت؟ تركت في وسط إفريقية عشرة ملايين إصابة بالإيدز، وهي تنشر 
لقد حكمت بالموت على من قال إن الأرض كرة تدور حول الشمس. أما اقتراف الخنا فحسب من فعله أن يعترف ويحيا آمنا! إن تزوير الدين على هذا النحو أزرى به، وزهَّد فيه، وأعطى الحكم العلماني ألف سبب ليحل محل الدين، وييتعد من الوحي كله... ونحن دعاة المسلمين نلقى العنت حين نقدم القرآن للناس لأن سيرة المسلمين مع دينهم لا تشرف، ولأن المعجبين بالحضارة الحديثة يروها أقرب إلى الفطرة والرشد... ولا بأس أن أحكي ما وقع لي أخيراً... جائتني رسالة من الأمين العام لمؤسسة كبرى تعمل على دعم الفضائل والقيم بين الناس، عقدت مؤتمرها الأول في "شيكاغو" وتستعد لعقد مؤتمرها الثاني لمناسبة مرور 50 عاماً على تأسيس هيئة الأمم المتحدة، وقيل لي بعد اختياري عضواً: إن مؤسستنا عالمية تضم رجالاً من كل دين سماوي أو أرضي، بل تضم أعضاء لا يؤمنون بأي دين. المهم أفم يدعمون الأخلاق الفاضلة، ويحترمون المثل العليا التي يجب أن تحكم العالم.

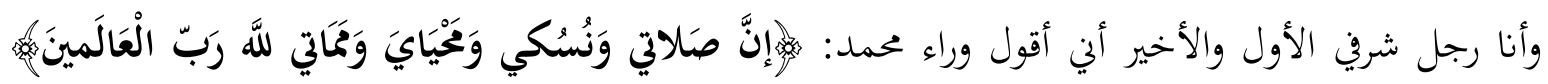
(الأنعام: 162-136). أنا أشعر حين آكل بأن الله هو الذي وضع اللقمة في فمي، وحين أفكر بأن الله هو الذي أسرج مصباح عقلي بأنه يستحيل أن أسوي بين مؤمن وكافر، أو أشترك مع عابد عجل أو عابد نفسه وحدها في عمل ما لرفع مستوى البشر...! شعرت بأن أهل الأديان تلاحقهم قمة خطيرة، أفم لا يهتمون بتزكية الروح، وأفم قد يدفعون المظالم عن أنفسهم، لكنهم لا يدفعوها عن غيرهم!، وأن طقوس العبادات ارجح لديهم من حقوق الإنسان، فكتبت رسالة مطولة أشرح فيها ديني، جاء فيها ما يلي: "شعرت بالرضا وأنا أقرأ عن إنشاء جهاز عالمي لدعم الأخلاق والتسامي بالبشر، وقلت إن الفطرة الإنسانية لا تزال طيبة تعشق الكمال وتسعى إليه، وتقاوم السعار المادي الذي يربط المرء بنفسه ومآربه وشهواته، ومعروف أن العالم تقاربت أقطاره واختصرت أبعاده، ونشأت فيه لأول مرة في تاريخه المديد- هيئة لأممه كلها، أي أن أبناء آدم أمسوا أسرة تستطيع التقارب والتحاور ودراسة ما يثور من مشكلات، والتعاون على حلها. لكنها ستعجز عن بلوغ أهدافها إلا في ظل الاكتمال الخلقي وكبت غرائز الأثرة والكبرياء، فهل نقصر في توفير الوسائل المنشودة لتحقيق ما نصبو إليه؟ إن نبي الإسلام يقو: "بعثت لأتمم مكارم الأخلاق"؛ ويقول لعي بن أب طال: "ألا أدلك على أكرم أخلاق الدنيا والآخرة؟ أن تصل من قطعك، وتعطي من حرمك، وتعفو عمن ظلمك"؛ ويقول لأصحابه: "ألا أخبركم بأفضل من درجة الصيام والصلاة والصدقة؟ قالوا: بلى! قال: إصلاح ذات البين، فإن فساد ذات البين هي الحالقة، لا أقول تحلق الشعر ولكن تحلق الدين"!! إننا نحن 
المسلمين يسعدنا تأليف هيئة أخلاقية تساند هيئة الأمم وتسدد خطاها وتحصنها من المحاباة والهوى... لكنني -ولأكن صريحاً- شعرت بحرج شديد عندما علمت أن "البرلمان" الأخلاقي فتح الباب للمؤمن والكافر، للموحد والمشرك، لمن يعتقد خلود الروح ولمن يرى انتهاء الوجود بالموت!. قد تقول: هذه الدنيا وهؤلاء أبناؤها، وقد تكونت الأمم المتحدة من ملل متناقضة تجاورت في مقاعدها لتدرس قضاياها المختلفة، وما تستطيع هيئة أخلاقية إلا أن تفعل ذلك! ولي على هذه الإجابة تعليق! إن النظر إلى الإيمان بالله على أنه قضية ثانوية أو قضية لا صلة لها بالأخلاق أمر مستنكر عندنا نحن المسلمين، أو هو أم يثير الاشمئزاز، لماذا يخلق الله ويُعبد غيره؟ ولماذا يعطي ويُشكر سواه؟ هل العقوق رذيلة إلا في معاملة الله؟!

إنني لو أجزلت العطاء لأحد ثم رأيته يجحدني لاشتد سخطي عليه واحتقاري له! كيف أرضى وجود أفراد أو جماعات تطعم من خير الله صباحاً ومساءً ثم تتجراً عليه، وتنكر وجوده وحقوقه؟ أعتقد أن منكري الألوهية ينبغي أن نعترف بكم، وإذا اضطررنا إلى مجالستهم فلنرسم لذلك سياسة خاصة توفق بين عقائدنا وحقهم في الحياة، من يدري؟ قد يهتدون إلى الصواب إذا حاسبناهم... - لق

"ومن دواعي سرورنا نحن المسلمين أن نلتقي بأتباع الديانات السماوية التي سبقتنا في مؤتمر جامع لتحسين الحسن وتقبيح القبيح وتقوية الفضائل ومحاربة الرذائل. إن لدينا الكثير الذي نود أن نقوله، والتراث الذي تركه لنا محمد صلى الله عليه وسلم لم يترك خطوة إلى الكمال إلا دعمها، ولا رغبة في التسامي إلا زّّاها وشجع عليها. إنه تراث ضخم تضمن مئات الصفحات الحافلة بمكارم الأخلاق، ولا أعرف رسولاً سماوياً ولا فيلسوفاً أرضياً خلّف مثل هذه إنه التركة!! ومن أراد الاطلاع أو الترجمة دلناه على المراجع التي يجتاج إليها... تم إننا نحن المسلمين نحب أن نتعرف على سلى الناس وأن يتعرف علينا الناس. هكذا علمنا ربنا.

فإن الله لم يخلق الأرض لنتهارش عليها ونسفك الدماء، بل خلقها لنرتفق خيره ونشكره عليه: وازهُوَ التَّي

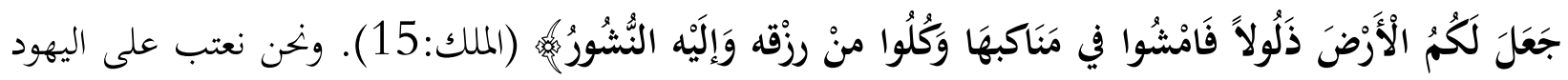
والنصارى أغم لم يبادلوا المسلمين المعاملة نفسها! قرأت أن يهودياً في مدينة الخليل استولى على بيت عربي، ثم قال لرب البيت: هذا البيت ملكي من بضعة آلاف عام وقد عاد إليّ، ولست أطلب منك أجرة سكناه طوال هذه القرون، لقد تنازلت عنها، فاذهب إلى أي مكان وأقم به أو اسكن في العراء إن شئت، ولا تعد هنا وإلا... هل 
تستقم علاقة إنسانية مع هذا المنطق؟! والسياسة الاستعمارية التي سيّت العالم في العصور الأخيرة كان هذا المنطق يكمن وراءها.

فإن الجريمة التي ارتكبها الإسلام - كما يرى بعضهم- أنه دحر الامبرطورية الرومانية التي كانت تحتل الأناضول وشرق البحر المتوسط ووادي النيل وشمال إفريقية وأقطار كثيرة أخرجها الإسلام منها وردها إلى أهلها الأولين، الذين اعتنقوا الإسلام بداهة...!!

وورثة الرومان ينظرون إلى مستعمراتم القديمة كأها أملاكهم الضائعة يجب أن يستعيدوها وإلى ملايين المسلمين

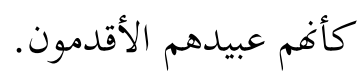

ولا شك أن قيام هيئة الأمم المتحدة على أسس إنسانية ججردة فتح صفحة جديدة في تاريخ العالم، وكفكف من غلواء الاستعمار السابق. لكن هل المنتصرون الذين بنوا هذه الهيئة النبيلة برئوا من سورات الحقد القديم وحاربوا التعصب والجشع؟ لعل إنشاء جهاز أخلاقي عالمي يساند الخصائص الإنسانية العليا وينشط الجهود المبذولة لدعمها ويصل بالهيئة إلى ما نريد ويقي العالم شرور الانقسام والخصام.

عن أبي ذر رضي الله عنه عن النبي صلى الله عليه وسلم فيما يرويه عن ربه عز وجل قال: "يا عبادي إني حرمت الظلم على نفسي وجعلته بينكم محرماً فلا تظالموا"، وفي الحديث أيضاً: "اتقوا الظلم فإن الظلم ظلمات يوم القيامة". والواقع أن من له دين يجب أن يكون شريفاً في رضاه وفي غضبه،فلا يستبيح خصماً، ولا يجوز على ضعيف، بل يقف عند الحق ويستريح للعمل، ويعلم أن النزق والجور من صفات السباع لا من خلائق الإنسان.

ويؤسفني أن الإنسانية في تاريخها الطويل احتالت على ارتكاب المظالم ورأت في اختلاف البشر -قوة وضعفاً، وغنئ وفقرا، وإيماناً وكفراً- ثغرة تنفذ منها إلى اقتراف ما تريد، وقد رفض القرآن الكريم أن يعترض العدالة شيء مادياً

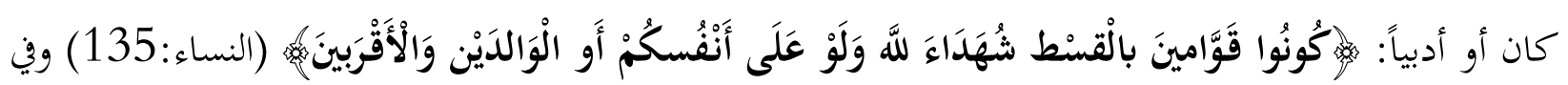

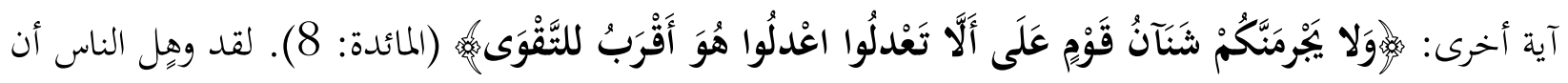
اختلاف الدين يبيح التظلم ويترك المجال رحباً للمشاعر المنحرفة والأهواء الجاعحة، وهذا كذب على رب الدين وباعث 


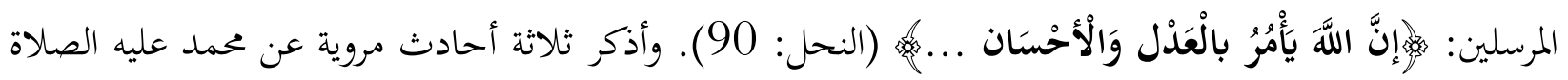
والسلام ترد هذه الفرية وتبرئ الإسلام من هذه التهمة.

الحديث الأول: "دعوة المظلوم مستجابة، وإن كان فاجراً ففجوره على نفسه".

والحديث الثاني: "دعوة المظلوم [وإن كان كافرا] ليس دوفها حجاب".

والحديث الثالث: عن أبي ذر قلت يا رسول الله ما كانت صحف إبراهيم؟ قال صلى الله عليه وسلم : "كانت

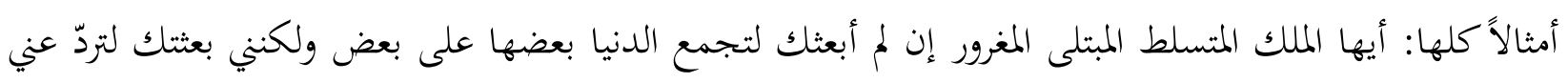

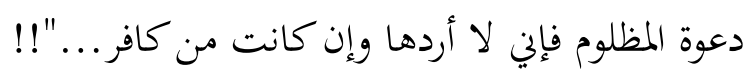

ومن دواهي الدهشة أن يموت نبي الإسلام ودرعه مرهونة عند يهودي في طعام اشتراه لأهله!.

$$
\text { ما أثر اختلاف الدين هنا؟ }
$$

إن اليهودي التائه عاش قرير العين موفور الدم والعرض والمال في عاصمة الإسلام! هل كانت غربته سبباً في أن

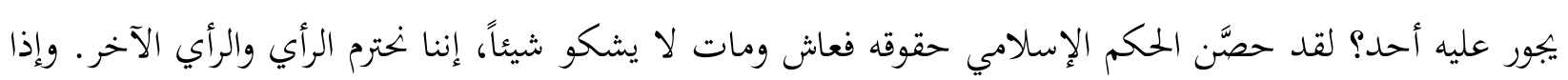

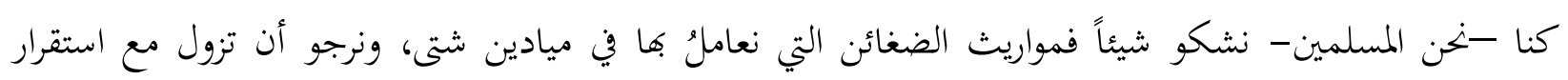

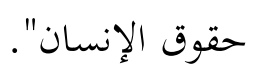

